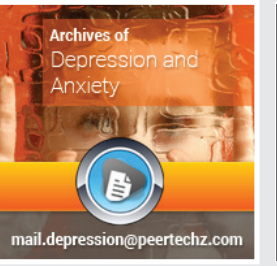

\title{
Monitoring problems in suicide action
}

Received: 24 February, 2020

Accepted: 05 June, 2020

Published: 06 June, 2020

*Corresponding author: Valach, Ladislav, PhD, Lindenstrasse 26, 3047 Berne, Switzerland, Tel.: ++41 79216 21 92; E-mail: ladislav.valach@swissonline.ch

https://www. peertechz.com
Valach Ladislav*

Private practice, Burgdorf, Switzerland
Check for updates

\begin{abstract}
Considering suicide in action terms and pointing out that it a distorted action, we describe some of the distortions as problems in self- and action- monitoring. Problems in pain, emotion and awareness as self- and action-monitoring systems were found in suicide actions and projects. We expanded these by the conception of a suicide action in its self-monitoring function. It monitors an inacceptable aggressive thought and action against a relevant other. The conception of suicide as a goaldirected action, on one hand, and the necessity of improving the self- and action-monitoring, on the other, facilitated the development of a brief clinical therapy program in which a reduction of the probability of a suicide attempt by $80 \%$ in 24 months was achieved.
\end{abstract}

\section{Suicide and action}

Suicide and suicide attempts are frequent events [1] and pose personal and social problems with severe consequences [2]. The analysis and explanation of suicide and suicide attempts received substantial professional attention [3] and also critique [4]. The existing empirical models of suicide processes contain a large number of variables ordered in a differentiated probabilistic relationship [5].

Suicide in modern times is mostly conceptualized in causal models [6]. Thus, the suicide processes are represented in causal or probabilistic events with the hope that these would help in developing a suicide preventive procedure [7].

Nevertheless, there still is work to be done [8]. There were voices introducing some of the elements of intentional processes into a suicide model, such as the motivationalvolitional three-phase model [9] and other [10,11]. However, although using the concept of intent, goal etc. these models remain in the frame of causal explanation.

There has also been a suggestion that suicide should be seen as a goal-directed process in form of action, project and career [12]. We further argued that these processes are joint and therefore social processes [13]. The view of suicide as a goaldirected action does not imply that all cases and all processes within the action-project-career frame are steered in a top down manner, as we illustrated in describing the bottom-up link of suicide action and suicide project [13].
Independently of the view whether suicide itself is a causal process or an intentional action, suicide preventive programmes require models of purposeful influencing and change of emotions, cognition and behaviour of the suicidal people. The proposed view of suicide as a goal-directed process in actions, projects and career presents a contrast to the conception of suicide as an illness [14]. This is an important distinction, then successful suicide preventive intervention relies on the agency processes of the suicidal clients or patients. However, it does not mean that suicide is an optimal, rational action. The goaldirected action development contains a number of distortions, mistakes, fallacies and omissions [15]. There are many parts in goal-directed processes that could go wrong. There could be goal problems (in an action, in a project, in a career), problems in the steps of action, project, career, problems in elements of action, project, career. Further there could be problems in the interrelationship of any levels of action with any levels of projects with any level of career organization. Further still, there could be problems in steering, controlling, regulation in action, project, career. Additionally, problems in energizing or in self- and action- monitoring. Not to forget the problems in the rendering of individual and joint action. Obviously, the most important problem is, in whatever one is engaged in, discounting the highest goal of staying alive!

We described a number of such problems and distortions and called suicide a distorted action [15]. However, it is important to maintain the conceptualization of suicide as an action because the suicide prevention must be based on the action intentionality of the suicidal person of which the patient 
is often stripped off when dealt with under the illness premises requiring passivity and surrender to treatment.

\section{Self-monitoring in suicide}

The distortions in the suicide action, project and career processes are often described or indicated by suicidal people in an interview. In our study using narratives and selfconfrontation interviews (a video supported recall) $[15,16]$ we found, among other, substantial problems in self- or action-monitoring. The self-monitoring problems in suicidal people were often previously discussed within a frame of dissociation $[17,18]$. We suggested that 'dissociation', while labelling the phenomenon, does not contribute much to its conceptualization, as it only provides a Latin name for an otherwise English word. Thus, we propose to see some of these processes in terms of self- and action- monitoring as a part of an action theoretical conceptualization. Self-monitoring or awareness is a brain and mental function that is an important part of consciousness/cognitive processes, emotion and pain. It is a part of action processes. It is an inherent property of a well-functioning system of action that all monitoring systems are adequately engaged when required. This does not have to be explicitly expressed as a postulate of a healthy living, but the common psychotherapy interventions directed at mindfulness, at awareness, at becoming emotionally sensitive and literate, at accepting pain (as well as many other procedures and goals in psychotherapy) suggest that [19-22].

The psychological monitoring properties were mostly discussed in the self-monitoring theory outlined by Snyder $[23,24]$. This implied a disposition, a habit or a process in which persons turned their attention to themselves being not only aware of their actions and their impact on others but also evaluating their own behaviour. The action selfmonitoring goes beyond this attitude toward oneself. It sees self-monitoring not only as a cognitive awareness process but also as a function of pain and emotion.

\section{Pain in its self-monitoring function}

Thus, self- and action- monitoring is seen as a function achieved by pain, emotional processes and awareness. However, pain is not identical with monitoring systems. It has been suggested that pain can be seen as caused (sensory), as monitoring (qualities) and as having consequences or being directed at an end (damage expectation) [25]. Thus, the selfmonitoring is one of the important functions of pain. The "third way" theories of pain address this issue [26].

The problems in monitoring as physical pain and pain in general in suicide were recognized early. Orbach proposed a disposition to insensitivity towards physical pain that he saw as a manifestation of dissociation [27]. Suicidality as a motivation to escape from and to end the unbearable psychological pain was described by Shneidman [28]. Baumeister [29] assumes that suicide is an escape from intolerable emotional pain. An elevated pain tolerance in suicidal persons by habituation is also an important part of the interpersonal theory of suicide [30].
We also addressed the issue of self- and action- monitoring in suicide as described by patients a few days after a suicide attempt and found that pain monitoring among other was reduced, particularly in repeated suicide [31].

We indicated several problems in the self-monitoring function of pain in suicide.

1. Patients reported not feeling physical pain while hurting themselves [15].

2. More patients who engaged in repeated suicide attempt reported not feeling any pain than first time suicide attempters [32].

3. Equally, some patients reported not feeling any pain while cutting themselves and starting to feel pain when realizing the severe consequences of their action [15].

\section{Self-monitoring function of emotion systems}

Another self- and action- monitoring function is often found in emotional systems. Generally, the emotional functions as being caused, providing a 'quick and dirty' first-hand evaluation of the situation and also "emoting", causing or leading to behaviour or action, are recognized. To distinguish among these functions different terms are used. Affect is describing processes around an impact, emotion is used around the readiness to motion (e-motion) and feeling is about monitoring. Emotions are essentially a part of the generation of motor activity, for which emotional evaluations are essential $[33,34]$. Some theorists maintain that the ultimate function of emotions is to activate and direct goal-related behaviors [35]. However, beforehand, emotions are also seen as a feedback, that is, a monitoring system [36] that enhances learning about the situation that elicited the emotion. Another differentiation provides the distinction between bottom-up and top-down emotions [37]. However, both are relevant in their monitoring function.

Emotions have been always considered relevant for suicide [38]. It has been suggested that unbearable emotions precede a suicide attempt $[39,40]$. Negative feelings towards oneself may be a contributor to suicidal ideation and behavior [41] Hopelessness is a risk factor for both suicidal ideation and behavior [42]. In addition to hopelessness, lower positive emotions and anxiety are the most significant emotional predictors of suicide attempts [43].

Higher negative emotions, anger and guilt, worthlessness are associated with having suicidal ideation [44]. Lack of emotional awareness may be a potential contributor to both suicidal desire and capability [45].

The emotional problems in suicide are also often addressed as problems in emotion dysregulation $[46,39]$. We reported that during the suicide act many suicide attempters and, particularly, the repeated suicide attempters do not emotionally monitor the extraordinary experiences of their suicide act in an adequate manner [31]. Thus, we propose that before the issue of emotion regulation is addressed, we have to deal with the problem of emotional monitoring during the suicide process. 
It is of interest that the monitoring systems of pain and emotion are not only interrelating, but that they can be used in a compensatory or vicarious manner. This is the case in various processes but certainly in suicide.

1. It has been established that pain takes over in expressing and embodying a strong negative emotion (psychache [40]. This also is addressed in the concept of somatizing [47].

2. Patients reported that while suffering emotional pain they did not feel physical pain [15].

3. Patients reported replacing physical pain by mental pain (as the mental pain was reported as more intensive, they suggested that this out weighted their physical pain, thus making it not accessible [15].

\section{Awareness in its self- and action- monitoring function}

The third self- and action- monitoring system could be seen in self- and action- awareness or cognitive monitoring in general. Cognition, meta-cognition [48], awareness, consciousness and self- and action- awareness and attention are distinct processes well differentiated in many models. For our purposes it is necessary to establish the monitoring function of these systems. These processes are often disputed as whether being caused or being steering faculties. Nevertheless, their monitoring function is seldom doubted and its impact on action and learning is often underlined. "Metacognitive monitoring is the gateway to self-regulating one's learning" [49].

In addition, as in pain and in emotional processes, it often is distinguished between bottom-up and top-down processing [50].

The problems in self-monitoring function of awareness were recognized as relevant in some psychiatric diagnoses [5153]. "A lack of self-monitoring will cause an inability to make the very rapid error corrections that depend upon being aware that the intended action is wrong rather than having to wait for the action to finish to observe its erroneous consequences" $[54,55]$. Consequently, a change in self-monitoring is seen as an important component in treatment of depression and suicidality. Across treatments, the most common components are psychoeducation, cognitive restructuring, activity scheduling, problem-solving, self-monitoring, and maintenance/relapse prevention, suicide risk assessment and safety planning [56]. The self-monitoring processes are not solely seen in phenomenological terms, but identified within the brain functionality. The brain's self-monitoring of activities, internal and external, is a functionality referred to as awareness and is key element of consciousness [57]. Equally, being addressed as self-referential processes they also become identified in neuropsychology research with practical implication for suicide prevention [58].

Once we turn to the practical implications of the concept of monitoring function of self- and action- awareness in an applied field [57,59], the issue becomes much clearer.
Consequently, its positive, constructive [60] and even suicide preventive functions can be discussed [61]. Nevertheless, awareness in regard to suicide is often identified as distorted or suicidal people are described as lacking emotional awareness [45]. Awareness as awareness of the suicide risks in others has also been addressed [62,63]. Although dealing in this paragraph with what generally is a cognitive realm we would like to go beyond the classification of the topic in cognitive content and information processing, on the one hand, and suicide distal and proximal processes, on the other [64]. We would like to understand self- and action- monitoring as a part or a function of and in action processes [65,66]. Here it is important to acknowledge that the most important distortion in cognitive or awareness self- and action- monitoring is the inability to monitor the complex goal hierarchy during suicide projects and actions. Particularly, the highest goal of surviving, as indicated above, is fully discarded from the monitoring of action and project in suicide.

The potential of constructive changes through self- and action- monitoring in awareness were often addressed. It has been suggested that performance-monitoring enables the rapid detection of mismatches between goals or intentions and actions, as well as subsequent behavioural adjustment by means of enhanced attention control [67]. Also, its suicide preventive potential became apparent. Self-monitoring is defined and detailed as a skill and skill deficit in cognitivebehavioral psychotherapy for suicidality [68].

Talking to suicidal patients or to patients after a suicidal attempt we detected certain disturbances in the awareness related self- and action- monitoring. Some patients indicated that a thought was disturbing and threatening to such a degree that they could monitor it in a form of pain. This function is often assumed in some psychopathology reasoning, such as in concepts of somatising and conversion. The clinical experience teaches us that strong and threatening emotions can be replaced by reported cognitive activity of monitoring environment that is not perceived by others. Thus, a patient describes unreal situations ("I found myself with my mother in a room with mirrors instead of walls, ceiling and floor"), instead of having or describing an emotion of existential insecurity, she experienced as a child.

Here the list of self- and action monitoring could end. In the dualistic conceptualization of inner and outer processes, of cognitive-emotional basis of external behaviour it might be the case. However, we would like to add another thought to consider in connection with self-monitoring. We know, and this not only because of a different philosophical stance, that the motor processes equally impact the cognitive-emotional processes [69-73] and that, therefore, the concept of action, containing internal, manifest and social processes, might be more appropriate [74]. Such a concept could be seen as a noncartesian conceptualization of human behaviour [75].

\section{Self-monitoring function of action}

In the contextual action-theory informed view all psychological processes are seen as an integral part of an 
action. Although, distinguishing among internal, manifest and social parts, but encompassing and integrating them, action theory does not follow the Cartesian conceptualization of separating cognitive from behavioural processes. Action processes (internal, manifest (and social) are complex and contain a number of sub-processes. Some of the action subprocesses (again, internal, external (and social) can be seen as consequences of, co-occurring with and preceding to other action sub-processes. In other words, action (emotion, cognition and behaviour) can be seen as caused which seems to be the mainstream view, or as being the primary cause of other changes, which would be the view of intentionality and teleology. However, action is and can also be conceptualized as mirroring, monitoring, being in recursive relation to other processes, internal, external (and social). Thus, the actionself-monitoring processes could be seen in this function as action integral and immanent. In their content, however, they can be the consequence of or preceding to other action processes. Learning more about the suicide action we have to propose that action could also be seen in its function as an action-self-monitoring process.

\section{Suicide as an action self-monitoring process in a group action}

This particularly is the case in a joint or group action that should be seen as composed of individual and group action level [76]. We pointed out that suicide is a joint and social process [13] and thus the action monitoring of this process could be conceptualized as a joint or group processes - thus monitoring in a group or joint action.

The monitored processes could be a very simple one as often addressed in suicide literature. A relationship of a suicidal person to a relevant other is threatening to such an extent that the person cannot bear it and attempts a suicide. In the words of group and individual action, an aggressive action step at a group level of action can be replaced by a suicidal step of an individual level of action.

\section{Suicide in a place of a self-forbidden thought and ac- tion}

In addition to this there also is another process invoking a caveat to a possible naïve phenomenology of all-inclusive conscious processes. This is the phenomenon and concept of "suicide action instead of a forbidden thought and action". Thus, next to the suicide processes of "because of" as in causal model, or "in order to" as in action model, we have the view of suicide as "instead of".

\section{Suicide as an action "instead of"}

\section{What is a suicide "instead of"?}

The thesis here is that suicide action could also be seen as an action in its self-monitoring function performed instead of having a thought and action that the person cannot accept or bear: that the other person in an important relationship wishes the suicidal person dead or that the suicidal person is frightened of a possible thought wishing to kill the primary care or any other relevant other. Maltsberger [77] formulated a similar idea as a part of various personal crises within a psychodynamic conceptualization based on the original formulation by Freud [78]. Thus, this process contains a number of sub-processes or arguments: (1) Suicide action, similarly to pain, emotion and cognitive awareness, could be seen in its self-monitoring function. (2) Self-monitoring processes could be „switched off". (3) It could be assumed that this switching off occurs under stressful circumstances, when seemingly unsolvable conflicts are experienced, when this ability of switching of is developed over a long time etc. (4) Thus self-monitoring could take over another self-monitoring capacity, such as pain instead of emotion, cognitive awareness instead of emotion, emotion instead of cognition, action instead of emotion or cognition. (5) Instead of having an inacceptable self-monitoring cognition, such as "the other person I am in an important relationship with wishes me dead or I could kill this other person because of what he/she has done to me" one can perform a suicide action under a seemingly illogical or oxymoronic reasoning. (6) This is further complicated by the fact that the destructive assumption is a part of overtly non-communicated information process in a joint action or project (that could be equal to unconscious individual cognition) and the suicide cognitive processes are individual processes.

Suicide prevention research offered in recent times a number of promising insights, models and theories indicating a better clinical application than many of the previous research studies. Motivational-volitional model, three-step theory, interpersonal theory of suicide and many other seem to provide a better clinical understanding. However, as many of the previous models, these are also locked in the desire to provide a probabilistic theory of suicide.

In contrast, it has been suggested that suicide should be understood and described in terms of goal-directed processes such as action, project and career [12,79]. Equally, this action understanding enables clinicians to employ the model of goaldirected action for framing the encounter with the suicidal person (Michel, Dey, Stadler, \& Valach, 2004), for framing the suicidal narrative [80] and for scaffolding the suicide prevention [81].

This action theory informed approach to suicide allows us to understand the key processes in different terms than previously.

While the analyses of the suicidal processes, as provided and described by suicidal people, are correct and understandable, the results expectation often do not make sense. We propose, that this is because the result is that the forbidden cognition is replaced by the suicide action step which the suicidal person often cannot understand themselves. Thus, though the suicide narrative provides information on the complex organization of the action systems of suicide and also provides steps of a ladder upon which the suicide prevention process could climb, the decisive forbidden conflict often stays hidden and would also be negated by the patient when confronted with it too early in the therapy process. Perhaps the acceptance of this conflict might not even be the decisive point in the suicide prevention. 
Traditionally, pain, emotion and cognitive awareness are considered the main action-self-monitoring processes. However, the above suggestion of an action in its selfmonitoring function does occur within the action theory informed understanding of suicide and could be seen as a subgroup of the "in order to" reasoning.

\section{Consequences for suicide preventive treatment and psychotherapy}

Some of the here suggested views, propositions and conceptualizations were justified by their suitability for and their facilitating effect on suicide prevention. 1) Allowing for a narrative of the suicide events will promote an action conceptualization in the joint communicative actions of a suicidal person and the psychotherapist. 2) Understanding suicide processes in action terms will enable the psychotherapists to accept this everyday common-sense action theory formulation of suicidal processes and stop them from analytically breaking down the events into probabilistic and causal chains. 3) It also promotes the view that an alternative life-related and -enhancing joint project instead of suicide project would have to be launched. Understanding the problems in selfand action-monitoring promotes strategies and procedures in psychotherapy and suicide prevention improving self- and action- monitoring. Being aware of the experiential nature of action and action change, particularly in suicidal processes in which the self- and action-monitoring is depleted, strategies and techniques would have to be used which do not exclusively rely on high level reflection. 4) For these purposes we use the self-confrontation interview. This consists of recording of the suicide narratives, replaying it to the interviewees, stopping the recording in short intervals of a few seconds or minutes and asking the interviewees to report on any thoughts, feelings and sensations they might have had during the recording while they were telling their stories. This interview is also recorded. We experienced that this procedure increases the self- and action-monitoring of the processes in question and thus might contribute to the suicide prevention. 5) Following this, the suicidal person is better able to consider alternatives to their suicide and other self-destructive strategies. 6) As a next step they can build up specific implementation intentions [82] for these alternative action steps. 7) In addition, regular encounters, written or telephone reminders etc. are required, in order to keep the joint suicide-alternative or life-enhancing project active [81]. Finally, as the existentially threatening hurtful relationship memory can only seldom be directly accessed and addressed - we remember, rather than becoming aware of this aggressive wish the person chooses suicide - the improved self- and action monitoring might help to distinguish between situationally specific action monitoring and memories of previously experienced threatening self-and action-monitoring. It is the latter that is monitored by the suicide action. It also is the latter that could be discounted, as not being situationally relevant and thus not required for an action dealing with the issues of "here and now". However, the decisive change is that the suicidal person becomes the agent of improving action monitoring and not the psychotherapist. Thus, the trap of psychotherapists getting involved in rescuing activities and thus promoting suicidal behaviour [83] can be avoided.

\section{Conclusion}

We proposed that suicide researchers describing suicidal people in dissociating and not feeling pain, showing problems in emotional experience and regulation and suffering cognitive biases and fallacies, overlook the larger picture, which is an action distortion as we described here in some sub-function of self- and action-monitoring. In addition, we maintain that the turning of the aggression against themselves the suicidal people often monitor in their action a deep conflict or a forbidden thought and action and perform a suicide action instead of threatening their primary carer or another relevant person in their life - a thought they cannot let enter their awareness. Based on this consideration we described several intervention steps (1-7) that help in improving the self- and action monitoring as well as framing the whole suicidealternative processes in terms of action and action project. This procedure proved to be very effective, as the probability of suicide attempts in the intervention group was reduced by more than $80 \%$ ( 24 month follow up) compared with the controlled group [84].

\section{References}

1. Olfson M, Blanco C, Wall M, Liu SM, Saha TD, et al. (2017) National trends in suicide attempts among adults in the United States. JAMA Psychiatry 74: 1095-1103. Link: https://bit.ly/309WkCz

2. Bellini S, Erbuto D, Andriessen $K$, Milelli M, Innamorati M, et al. (2018) Depression, hopelessness, and complicated grief in survivors of suicide. Front Psychol 9: 198 Link: https://bit.ly/2zanvlK

3. O'Connor RC, Nock MK (2014) The psychology of suicidal behaviour. The Lancet Psychiatry 1: 73-85 Link: https://bit.ly/2z8Hhhq

4. Braquehais MD, Madoz-Gúrpide A (2012) Theoretical and methodological weaknesses of current psychiatric models of suicidal behavior. In AM Columbus (Ed.), Adv Psychol Res 131-138.

5. Franklin JC, Ribeiro JD, Fox KR, Bentley KH, Kleiman EM, et al. (2017) Risk factors for suicidal thoughts and behaviors: A meta-analysis of 50 years of research. Psychological Bulletin 143: 187-232. Link: https://bit.ly/2z44Ckb

6. Nock MK (2009) Suicidal behavior among adolescents: Correlates, confounds, and (the search for) causal mechanisms. Journal of the American Academy of Child \& Adolescent Psychiatry 48: 237-239. Link: https://bit.ly/307baK5

7. Wasserman D (2016) Suicide: An unnecessary death, 2nd ed. New York, NY US: Oxford University Press.

8. Nock MK (2016) Recent and needed advances in the understanding, prediction, and prevention of suicidal behavior. Depression and Anxiety 33: 460-463. Link: https://bit.ly/3eOKYbh

9. O'Connor RC (2011) Towards an integrated motivational-volitional model of suicidal behaviour. In RC O'Connor, S Platt, J Gordon (Eds.), International handbook of suicide prevention: Research, policy and practice. Chichester, United Kingdom: Wiley 181-198. Link: https://bit.ly/371WUnj

10. Leenaars AA, Lester D, Yang B (1992) Menninger's motives for suicide in the notes of completed and attempted suicides. Psychological Reports 70: 369370. Link: https://bit.ly/2XxRNIk

11. Meyer CL, Irani TH, Hermes KA, Yung B (2017) Explaining suicide: Patterns motivations, and what notes reveal. San Diego, CA, US: Elsevier Academic Press.

12. Michel K, Valach L (2002) Suicide as goal-directed action. In Ed. K. van 
Heeringen (Ed.), Understanding suicidal behaviour: The Suicidal process approach to research and treatment. Chichester: Wiley \& Sons 230-254.

13. Valach L, Michel K, Young RA, Dey P (2006b) Linking life and suicide related goal directed systems. J Mental Health Couns 28: 353-372. Link: https://bit.ly/2Uavbes

14. Valach L, Young RA, Michel K (2011) Understanding suicide as an action. In K. Michel \& D. A. Jobes (Eds.), Building a therapeutic alliance with the suicidal patient. Washington DC: American Psychological Association 129-148.

15. Valach L, Michel K, Young RA (2016) Suicide as a distorted goal-directed process: Wanting to die, killing, and being killed. J Nerv Ment Dis 204: 812 819. Link: https://bit.ly/2AJEU5e

16. Valach L, Michel K, Dey P, Young RA (2002) Self-confrontation interview with suicide attempters. Counselling Psychology Quarterly 15: 1-22. Link: https://bit.ly/2Udd9IT

17. Firestone L (2018) Dissociation and therapeutic alliance. In M. Pompili (Eds.), Phenomenology of suicide. Cham: Springer 167-186.

18. Orbach I, Kedem P, Herman L, Apter A (1995) Dissociative tendencies in suicidal, depressed, and normal adolescents. J Social Clin Psychol 14: 393408. Link: https://bit.ly/2MxKvOE

19. Baer RA (2006) Mindfulness-based treatment approaches: Clinician's guide to evidence base and applications. San Diego: Academic Press.

20. Brown K, Ryan R (2003) The benefits of being present: mindfulness and its role in psychological well-being. J Personality Social Psychol 84: 822-848. Link: https://bit.ly/2UckzMO

21. Linehan M (1993) Skills training manual for treating borderline personality disorder. New York: Guilford Press.

22. Segal ZV, Williams M, Teasdale J (2002) Mindfulness-based cognitive therapy for depression: A new approach to preventing relapse. New York: Guilford Press.

23. Snyder M (1974) Self-monitoring of expressive behavior. J Personality Social Psychol 30: 526-537. Link: https://bit.ly/30cg7Bs

24. Snyder M, Gangestad S (2000) Self-monitoring: Appraisal and reappraisal Psychological Bulletin 126: 530-555. Link: https://bit.ly/2Xxftg6

25. Price DD (2017) A view of pain based on sensation, meaning and emotion In J. Corns (Ed.), The Routledge handbook of philosophy of pain. London: Routledge. 113-123.

26. Williams AC (2017) Psychological models of pain. In J. Corns (Ed.), The Routledge handbook of philosophy of pain. London: Routledge 143-153.

27. Orbach I (1994) Dissociation, physical pain, and suicide: A Hypothesis. Suicide and Life-Threatening Behavior 24: 68-79. Link: https://bit.ly/2Mx9jGk

28. Shneidman ES (1996) The suicidal mind. New York, NY: Oxford University Press.

29. Baumeister RF (1990) Suicide as escape from self. Psychological Review 97 90-113. Link: https://bit.ly/2Y1bml1

30. Van Orden KA, Witte TK, Cukrowicz KC, Braithwaite SR, Selby EA, et al. (2010) The interpersonal theory of suicide. Psychol Rev 117: 575-600. Link https://bit.ly/2BALkE5

31. Valach L, Young RA (2018) No feeling during repeated suicide attempt: A Qualitative study. J Psychiatry 21: 460. Link: https://bit.ly/2A72ZCK

32. Valach L, MichelK, Young RA (2018) Self-reports of corrective experiences by suicide attempters in a video self-confrontation. J Psychiatry Studies 1: 101. Link: https://bit.ly/3eVAabt
33. Averill J (1980) A constructivist view of emotion. In R Plutchik, H Kellerman (Eds.), Emotion theory research and experience. Academic Press: New York 1: $305-340$

34. Frijda NH (2000) The psychologists' point of view. In M Lewis, JM Haviland (Eds.), Handbook of emotions. New York, NY: Guilford Press. 2nd ed, 59-74.

35. Cosmides L, Tooby J (2000) Evolutionary psychology and the emotions. In M Lewis \& J. M. Haviland (Eds.), Handbook of emotions. New York, NY: Guilford Press. 2nd ed. 91-115.

36. Baumeister RF, Vohs KD, DeWall CN, Zhang L (2007) How emotion shapes behavior: Feedback, anticipation, and reflection, rather than direct causation. Personality and Social Psychology Review 11: 167-203. Link: https://bit.ly/3gUim24

37. McRae K, Misra S, Prasad AK, Pereira SC, Gross JJ (2011) Bottom-up and top-down emotion generation: Implications for emotion regulation. Socia Cognitive and Affective Neuroscience 7: 253-262. Link: https://bit.ly/3dAPeux

38. Kiosses DN, Szanto K, Alexopoulos GS (2014) Suicide in older adults: The Role of emotions and cognition. Curr Psychiatry Rep 16: 495. Link: https://bit.ly/2UsNaxx

39. Rajappa K, Gallagher M, Miranda R (2012) Emotion dysregulation and vulnerability to suicidal ideation and attempts. Cognit Ther Res 36: 833-839. Link: https://bit.ly/2Ucaz50

40. Shneidman ES (1993) Suicide as psychache. J Nerv Ment Dis 181: 145-147. Link: https://bit.ly/2Y9tYpA

41. Scott LN, Wright AGC, Beeney JE, Lazarus SA, Pilkonis PA, et al. (2017) Borderline personality disorder symptoms and aggression: A withinperson process model. J Abnormal Psychol. 126: 429-440. Link: https://bit.ly/2MwQZNz

42. Cukrowicz KC, Duberstein PR, Vannoy SD, Lynch TR, McQuoid DR, et al. (2009) Course of suicide ideation and predictors of change in depressed older adults. J Affect Disord 113: 30-36. Link: https://bit.ly/2XxuEWz

43. Seidlitz L, Conwell Y, Duberstein P, Cox C, Denning D (2001) Emotion traits in older suicide attempters and non-attempters. J Affect Disord 66: 123-131. Link: https://bit.ly/3h5UcBY

44. Lynch TR, Johnson CS, Mendelson T, Robins CJ, Ranga K, et al. (1999) Correlates of suicidal ideation among an elderly depressed sample. J Affect Disord 56: 9-15. Link: https://bit.ly/2Y5ijrA

45. Baer MM, LaCroix JM, Browne JC, Hassen HO, Perera KU, et al. (2018) Lack of emotional awareness is associated with thwarted belongingness and acquired capability for suicide in a military psychiatric inpatient sample. Suicide and Life-Threatening Behavior. Advance online publication. Link: https://bit.ly/309zWJu

46. Law KC, Khazem LR, Anestis MA (2015) The role of emotion dysregulation in suicide as considered through the ideation to action framework. Curr Opinion Psychol 3: 30-35. Link: https://bit.ly/3cuYeAc

47. Servan-Schreiber D (1998) Coping effectively with patients who somatize Women's Health Primary Care 1: 435-447.

48. Flavell JH (1979) Metacognition and cognitive monitoring: A new area of cognitive-developmental inquiry. Ame Psychol 34: 906-911. Link: https://bit.ly/2Y1XYZ8

49. Winne PH, Perry NE (2000) Measuring self-regulated learning, In M Boekaerts, PR Pintrich, M Zeidner (Eds.), Handbook of self-regulation. Orlando, FL: Academic Press 531-566. Link: https://bit.ly/3cAbl31

50. Rieger K, Diaz Hernandez L, Baenninger A, Koenig T (2016) 15 years of microstate research in schizophrenia-Where are we? A meta-analysis. Frontiers Psychiatry 7: Article ID 22. Link: https://bit.ly/3czBIpO 
51. Blackmore S, Smith J, Steel R, Johnstone E, Frith C (2000) The perception of self-produced sensory stimuli in patients with auditory hallucinations and passivity experiences: Evidence for a breakdown in self-monitoring. Psychol Med 30: 1131-1139. Link: https://bit.ly/3eVAXZZ

52. Fairer C, Frith CD (2001) Experiencing oneself vs another person as being the cause of an action: The neural correlates of the experience of agency. Neuroimage 15: 956-603. Link: https://bit.ly/3dA7Yuv

53. Frith CD, Blakemore SJ, Wolpert DM (2000) Abnormalities in the awareness and control of action. Philosl Trans R Soc Lond B Biol Sci 355: 1771-1788. Link: https://bit.ly/2AGtwqJ

54. Frith C (2005) The self in action: Lessons from delusions of control. Consciousness and Cognition: An Int J 14: 752-770. Link: https://bit.ly/2Ubz57q

55. Gallagher S (2004) Neurocognitive models of schizophrenia: A Neurophenomenological critique. Psychopathol 37: 8-19. Link: https://bit.ly/2MvLLIh

56. Bose D, Pettit JW (2018) Depression. In S. Hupp (Ed.), Child and adolescent psychotherapy: Components of evidence-based treatments for youth and their parents. New York, NY, US: Cambridge University Press 138-153.

57. Fontanari JF (2017) Awareness improves problem-solving performance Cognitive Systems Res 45: 52-58. Link: https://bit.ly/2XCkMuN

58. Quevedo K, Ng R, Scott H, Martin J, Smyda G, et al. (2016) The neurobiology of self-face recognition in depressed adolescents with low or high suicidality. $J$ Abnormal Psychol 125: 1185-1200. Link: https://bit.ly/309M4KD

59. Chow GM, Luzzeri M (2019) Post-event reflection: A tool to facilitate selfawareness, self-monitoring, and self-regulation in athletes. J Sport Psycho Action. Link: https://bit.ly/2UaHnfR

60. Gardner FL, Moore ZE (2007) The psychology of enhancing human performance: The Mindfulness-Acceptance-Commitment (MAC) approach New York, NY, US: Springer Publishing Co.

61. Silvia PJ. O'Brien ME (2004) Self-awareness and constructive functioning: Revisiting "the human dilemma". J Social Clin Psychol 23: 475-489. Link: https://bit.ly/3gVAfOc

62. Arendt F, Scherr S, Niederkrotenthaler T, Krallmann S, Till B (2018) Effects of awareness material on suicide-related knowledge and the intention to provide adequate help to suicidal individuals. Crisis: J Crisis Interven Suicide Preven 39: 47-54. Link: https://bit.ly/2Xz9Ai

63. Kong L, Sareen J, Katz LY (2016) School-based suicide prevention programs. In R. C. O'Connor, J Pirkis (Eds.), The international handbook of suicide prevention. Chichester: Wiley 725-742.

64. Wenzel A, Spokas M (2014) Cognitive and information processing approaches to understanding suicidal behaviors. In MK Nock (Ed.), The Oxford handbook of suicide and self-injury. Oxford: Oxford University Press 235-254. Link: https://bit.ly/2UeLely

65. von Cranach M, Kalbermatten U, Indermuehler K, Gugler B (1982) Goal directed action. London: Academic Press.

66. Valach L, Lynam MJ, Young RA (2002) Action theory. A primer for applied research in the social sciences. Westport, CT: Praeger. Link: https://bit.ly/2A3tKlo

67. De Saedeleer L, Gilles Pourtois G (2016) Evaluative priming reveals dissociable effects of cognitive versus physiological anxiety on action monitoring. Emotion 16: 498-514. Link: https://bit.ly/2Y3Rbt1
68. Rudd MD, Joiner T, Rajab MH (2001) Treating suicidal behavior. New York: The Guilford Press.

69. Jackson PL, Decety J (2004) Motor cognition: a new paradigm to study self-other interactions. Curr Opin Neurobiol 14: 259-263. Link: https://bit.ly/3gXJUDV

70. Jeannerod M (2001) Neural simulation of action: A Unifying mechanism for motor cognition. Neurolmage 14: 103-S109. Link: https://bit.ly/2Y9vzvA

71. Leisman G, Moustafa, Shafir T (2016) Thinking, walking, talking: Integratory motor and cognitive brain function. Front Public Health 4: 94. Link: https://bit.ly/3cGHEh2

72. Moreau D (2012) The role of motor processes in three-dimensional mental rotation: Shaping cognitive processing via sensorimotor experience. Learning and Individual Differences 22: 354-359. Link: https://bit.ly/3gTz5CF

73. Rizzolatti G, Fadiga L, Gallese V, Fogassi L (1996) Premotor cortex and the recognition of motor actions. Cognitive Brain Res 3: 131-141. Link: https://bit.ly/2BsQamc

74. Valach L, Young RA (2015) Suicide and counseling for suicidality. In RA Young JF Domene, L Valach, (Eds.), Counseling and action. Toward life-enhancing work, relationship, and identity. New York: Springer. 295-313.

75. Valach L (2020) Non-Cartesian view of suicide and suicide prevention intervention. J Psychosoc Rehabil Ment Health. Link: https://bit.ly/3dBz986

76. von Cranach M, Ochsenbein G, Valach L (1986) The group as a self-active system: outline of a theory of a group action. Eur J Social Psychol 16: 193 229. Link: https://bit.ly/2Y1nSr7

77. Maltsberger JT (1986) Suicide risk: The formulation of clinical judgment. New York, NY: New York University Press.

78. Richman J, Rosenbaum M (1996) A clinical study of the role of hostility and death wishes by the family and society in suicidal attempts. In JT. Maltsberger, MJ Goldblatt (Eds.), Essential papers on suicide. New York: New York University Press. 221-242.

79. Michel K, Valach L (1997) Suicide as goal directed action. Arc Suicide Res 3 213-221. Link: https://bit.ly/2Y22dz4

80. Michel K, Valach L (2011) The narrative interview with the suicidal patient. In K. Michel \& D. A. Jobes (Eds.), Building a therapeutic alliance with the suicidal patient. Washington DC: American Psychological Association. 63-80.

81. Michel K, Valach L, Gysin-Maillart A (2017) A novel therapy for people who attempt suicide and why we need new models of suicide. Int J Environ Res. Public Health 14: 243. Link: https://bit.ly/2XyMxUJ

82. Gollwitzer PM (1999) Implementation intentions: Strong effects of simple plans. Ame Psychol 54:493-503. Link: https://bit.ly/2Y6fGpB

83. Hendin H (1996) Psychotherapy and suicide. In: JT. Maltsberger \& MJ. Goldblatt (Eds.), Essential papers on suicide. New York: New York University Press. 427-441.

84. Gysin-Maillart A, Schwab S, Soravia L, Megert M, Michel K (2016) A novel brief therapy for patients who attempt suicide: A 24-months follow-up randomized controlled study of the attempted suicide short intervention program (ASSIP). PLoS Med 13: e1001968. Link: https://bit.ly/2z5wl49

85. Schnyder U, Valach L, Bichsel DK, Michel K (1999) Do we understand the patients' reasons? Gen Hospital Psychia 21: 62-69.

Copyright: ( 2020 Ladislav V. This is an open-access article distributed under the terms of the Creative Commons Attribution License, which permits unrestricted use, distribution, and reproduction in any medium, provided the original author and source are credited. 